\title{
Brain Dead Presentation of Snake Bite
}

\author{
Sonika Agarwal, Nidhi Kaeley ${ }^{1}$, Sushant Khanduri, Nand Kishore \\ Departments of Critical Care Medicine and 'Medicine, HIMS, SRHU, Dehradun, Uttarakhand, India
}

\section{Abstract}

Snakebite is considered as a significant public health problem contributing considerably to morbidity and mortality. A neurotoxic snake bite can present from mild ptosis to complete paralysis with external and internal ophthalmoplegia. Three patients presented in emergency intubated outside with deeply comatose, fixed dilated pupil, and absent doll's eye reflex mimicking as brain dead.

Keywords: Braindead, snake envenomation, supportive care

\section{INTRODUCTION}

Snakebite envenomation is a global concern now recognized as "neglected tropical disease" by the World Health Organization. Worldwide approximately 5 million people are bitten by snake every year with 100,000 deaths and 300,000 amputations and permanent disabilities. Majority of snake bite deaths occurs in Asia and Sub-Saharan Africa. India has the highest snakebite mortality in the world with estimated mortality in between 35,000 and 50,000 per year. ${ }^{[1]}$ Combination of internal and external ophthalmoplegia can mimic-like brain dead as in these reported cases which are rare and produces a diagnostic dilemma. ${ }^{[2]}$ Such cases are reported by four authors and just by continuing supportive care can lead to the excellent outcome.

\section{Case Reports}

\section{Case 1}

An 18-year-old male was sleeping on the floor after taking dinner woke up at 4:00 am with pain abdomen, vomiting, and weakness. He was taken to a hospital in the comatose state where he was intubated and referred to our hospital with a provisional diagnosis of unknown poisoning. There was no history of snake bite and no fang mark. At admission, he was atonic with the Glasgow coma scale (GCS) of E1VTM1, areflexia, pupils were dilated and fixed with absent doll's eye reflex and no respiratory efforts. He was immediately shifted to the Intensive Care Unit (ICU). His pulse rate was $120 /$ min and blood pressure was $120 / 60 \mathrm{SpO}_{2} 98 \%$ with no respiratory efforts. His first arterial blood gas was suggestive

\begin{tabular}{|l|l|}
\hline \multicolumn{3}{|c|}{ Access this article online } \\
\hline Quick Response Code: & Website: \\
& www.ijccm.org \\
\hline
\end{tabular}

of respiratory acidosis. He was ventilated on synchronized intermittent mandatory ventilation with volume control mode of ventilation. His initial investigation were all within the normal limit with normal computed tomography (CT) brain and ultrasound abdomen except total leukocyte count (TLC) count of 28.96 thou/cumm S. K-5.18 mmol/L and aspartate aminotransferase/alanine aminotransferase (U/L)-138/100. Fundus examination showed normal disc. He was managed with broad-spectrum antibiotics, antacids, and mechanical ventilation. Polyvalent anti-snake venom (ASV) therapy was started immediately, and the total of $100 \mathrm{ml}$ was given with provisional diagnosis of severe envenomation. After $8 \mathrm{~h}$, he started slight flickering in fingers and eyes and started having some respiratory efforts. The same dose of ASV dose was repeated after $12 \mathrm{~h}$. The paralysis improved and was extubated on the $4^{\text {th }}$ day of ventilation. TLC, liver enzymes and S. Potassium came in normal range. Antibiotics were stepped down. When he was shifted out of ICU on the $4^{\text {th }}$ day, he has Grade 4 power in upper and lower limb and breathing well but had truncal muscle weakness. Pupils were mid-dilated sluggishly reacting and otherwise stable.

\section{Case 2}

A 38-year-old male with no comorbid illness had a sensation of some insect on the skin and slept in a night on the floor. Next

Address for correspondence: Dr. Sonika Agarwal, B18/8, HIMS Campus, HIMS, Jolly Grant, Dehradun - 248 016, Uttarakhand, India. E-mail: sonikakatiyar@srhu.edu.in

This is an open access journal, and articles are distributed under the terms of the Creative Commons Attribution-NonCommercial-ShareAlike 4.0 License, which allows others to remix, tweak, and build upon the work non-commercially, as long as appropriate credit is given and the new creations are licensed under the identical terms.

For reprints contact: reprints@medknow.com

How to cite this article: Agarwal S, Kaeley N, Khanduri S, Kishore N. Brain dead presentation of snake bite. Indian J Crit Care Med 2018;22:541-3. 
morning at 4:00 am, he developed respiratory weakness which was rapidly progressive. He was admitted to local hospital where he was intubated and was mechanically ventilated. He was referred to our hospital where on examination, he had GCS of E1VTM1, areflexia, pupils were dilated and fixed and no spontaneous respiratory efforts. All investigations were within normal limit, and CT scan brain was normal. He was shifted to ICU and was managed supportively. Magnetic resonance imaging (MRI) brain and cerebrospinal fluid analysis were performed which were within normal limit. A presumptive diagnosis of snake bite was made, and ASV $100 \mathrm{ml}$ intravenous over $1 \mathrm{~h}$ was given and the second dose of $100 \mathrm{ml}$ was repeated after $12 \mathrm{~h}$. Supportive management and mechanical ventilation were continued. Next day patient tried to open his eyes slightly on verbal commands. The patient improved gradually and wean off from the ventilator on the $4^{\text {th }}$ day and shifted to ward on the $5^{\text {th }}$ day of ICU admission.

\section{Case 3}

A 30-year-old male presented with pain abdomen, loose stools, and vomiting after waking up early in the morning and rapid-onset breathlessness with weakness and frothing from the mouth. He was immediately taken to some private hospitals where he was intubated in view of $\mathrm{CO}_{2}$ narcosis and referred to higher center. In an emergency, the patient was received with GCS of E2VTM1, pupils B/L 5 mm not reacting to light, hemodynamically stable, no respiratory efforts on artificial manual breathing unit. The patient was immediately shifted to ICU. In ICU GCS deteriorated to E1V1M1 with no brain stem reflexes. All investigations were within normal limit except slight respiratory acidosis which improved with mechanical ventilation. Neurologist opinion was taken, and they diagnosed him to be brain dead after doing apnea test. Fundus examination was normal. MRI brain was done which was normal. Empirically, ASV and neostigmine were given on the $2^{\text {nd }}$ day, and the dose was repeated. Calorie test was done by an ear-nose-throat surgeon who reported normal functioning of labyrinths. The slight flickering of eyes was noted on the $5^{\text {th }}$ day, and supportive management of patient continued. The patient developed complications of tube block, ventilator-associated pneumonia with septic shock during his ICU stay which was managed with antibiotics, i. v fluids and vasopressors and patient was tracheostomized. Gradually, the patient recovered weaned off from ventilator after 15 days of mechanical ventilation and shifted to ward after 18 days and discharged from hospital in 29 days. Retrospectively, patient gave the history of snake bite.

\section{Discussion}

Snake bite remains an underestimated cause of accidental or occupational death in modern India. ${ }^{[3]}$ Snake bite is a common medical emergency. Males suffer twice more than females. About $50 \%$ bites are dry bites that result in negligible envenomation. The three major families of venomous snakes are the Elapidae, the Viperidae, and the hydrophiidae. Elapidae includes cobra, king cobra, krait, and coral snake which are neurotoxic. The most commonly found snakes in North India are from Elapidae family.

Neuroparalysis in the neurotoxic snake is due to blockade of neuromuscular receptors pre- and post-synaptically in krait bite and postsynaptically in cobra bite. Bite by the Indian cobra (Naja naja) results in tender local swelling, blistering, and necrosis while skin manifestation is not present in krait bite. The common krait is nocturnally active with painless bite. ${ }^{[3]}$ Nausea, vomiting, malaise, prostration, and abdominal pain are the usual initial systemic symptoms. Paralysis begins within the $1^{\text {st }} \mathrm{h}$ is heralded by ptosis, followed by external ophthalmoplegia followed by distal muscles. Diaphragm and pupils are the most resistant to the neurotoxin. Respiratory failure is the usual cause of death. ${ }^{[4]}$ Internal ophthalmoplegia occurs due to autonomic dysfunction which mimics brain dead. ${ }^{[5]}$ Recovery is slow with krait envenomation due to irreversible binding of the toxin to pre-synaptic receptors and duration varies from $30 \mathrm{~h}$ to 6 days.

Krait bite usually leaves no distinct fang marks. In the absence of history and patients denial to the history of snake bite, it is the physician's strong clinical skill to diagnose a case of snake bite. The patient may be misdiagnosed when he complains of severe abdominal pain and vomiting.

Clinical recovery is slow in both pre- or post-synaptic blockade by snake venom. Sometimes, neurologist misdiagnoses it as a case of brain dead and may prompt withdrawing ventilatory support. In such cases, other tests of brain dead such as electroencephalography, transcranial Doppler ultrasonography, cerebral angiography, or radionuclide imaging should be considered, and supportive management should be continued. ${ }^{[2]}$ Supportive care should be continued until the effect of venom remains, and recovery is excellent.

In all the above cases, the clinical scenario appears to be a painless krait bite in the night. ${ }^{[6]}$ Similar cases are reported by Azad et al. from Chandigarh, ${ }^{[7]}$ John et al., ${ }^{[2]}$ Dayal et al., ${ }^{[8]}$ and Prakash et al. ${ }^{[9]}$ Hence, the clinicians must be aware of brain dead presentation of snake bite especially after rains, after floods, during harvest, and at night. Withdrawing the supportive care might be disastrous.

\section{Declaration of patient consent}

The authors certify that they have obtained all appropriate patient consent forms. In the form the patient(s) has/have given his/her/their consent for his/her/their images and other clinical information to be reported in the journal. The patients understand that their names and initials will not be published and due efforts will be made to conceal their identity, but anonymity cannot be guaranteed.

Financial support and sponsorship

Nil.

Conflicts of interest

There are no conflicts of interest. 


\section{References}

1. Kasturiratne A, Wickremasinghe AR, de Silva N, Gunawardena NK, Pathmeswaran A, Premaratna R, et al. The global burden of snakebite: A literature analysis and modelling based on regional estimates of envenoming and deaths. PLoS Med 2008;5:e218.

2. John J, Gane BD, Plakkal N, Aghoram R, Sampath S. Snake bite mimicking brain death. Cases J 2008;1:16.

3. Warrell DA. WHO/SEARO guidelines for the clinical management of snakebite in the Southeast Asian region. SE Asian J Trop Med Public Health 1999;30:1-85.

4. Warrell DA. Injuries, envenoming, poisoning, and allergic reactions caused by the animal. In: Warrell DA, Cox TN, Firth JD, Benj J Jr., editors. Oxford
Textbook of Medicine. Oxford University Press; 2003. p. 923-45.

5. Kularatne SA. Common krait (Bungarus caeruleus) bite in Anuradhapura, Sri Lanka: A prospective clinical study, 1996-98. Postgrad Med J 2002; 78:276-80.

6. Wijdicks EF. The diagnosis of brain death. $\mathrm{N}$ Engl J Med 2001;344:1215-21.

7. Azad C, Mahajan V, Jat KR. Locked-in syndrome as a presentation of snakebite. Indian Pediatr 2013;50:695-7.

8. Dayal M, Prakash S, Verma PK, Pawar M. Neurotoxin envenomation mimicking brain death in a child: A case report and review of literature Indian J Anaesth 2014;58:458-60.

9. Prakash S, Mathew C, Bhagat S. Locked-in syndrome in snakebite. J Assoc Physicians India 2008;56:121-2. 